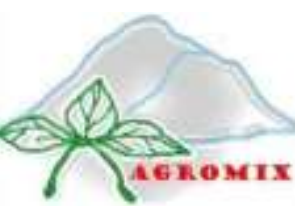

\title{
AGROMIX
}

Jurnal IImiah Fakultas Pertanian, Universitas Yudharta Pasuruan

pISSN (Print): 2085-241X; elSSN (Online): 2599-3003

Website: https://jurnal.yudharta.ac.id/v2/index.php/agromix

\section{Pengaruh Lama Fermentasi terhadap aktivitas antioksidan minuman fermentasi kombucha lengkuas merah (Alpinia purpurata)}

\section{Effect of fermentation time on antioxidant activity of kombucha red galangal (Alpinia purpurata) fermented beverage}

\author{
Martina Widhi Hapsari ${ }^{1 *}$, Windy Rizkiprilisa ${ }^{1}$, Agnes Prawistya Sari ${ }^{2}$ \\ ${ }^{1}$ Program Studi Teknologi Pangan, Fakulta Sains dan Teknologi, Universitas Nasional Karangturi, Semarang, Jawa Tengah \\ ${ }^{2}$ Program Studi Farmasi, Fakultas Ilmu Kesehatan, Universitas Kusuma Husada, Surakarta, Jawa Tengah \\ *Email korespondensi: martina.widhi@unkartur.ac.id
}

\section{Article History}

Received : August 01, 2021

Accepted : September 15, 2021

Published : September 28, 2021

Keyword

Antioxidant; fermentation time; kombucha; red galangal

\section{ABSTRACT}

Fermentation is one way to increase bioactive compounds in various food products. Kombucha is a beverage product from traditional fermentation which involves fermenting sugar dissolved in tea with symbiotic culture of bacteria and yeast (SCOBY). Kombucha is usually made from a tea solution and not many use spices to make kombucha. In this study, red galangal kombucha will be made. The method used was Completely Randomized Design (CRD) with a variation of fermentation time $(0,2,4,6,8$ 10) days. Parameters to be analyzed are $\mathrm{pH}$, total phenol, and antioxidant activity. Tujuan dari penelitian ini adalah mengetahui aktivitas antioksidan yang optimal dan pengaruh $\mathrm{pH}$ terhadap lama ferementasi pada kombucha lengkuas merah. The results obtained are that the length of fermentation affects $\mathrm{pH}$, total phenolic and antioxidant activity of red galangal kombucha drink. The $\mathrm{pH}$ of the red galangal kombucha drink decreased along with the length of fermentation. The most optimal total phenolic and antioxidant activity obtained at 8 days of fermentation were $854.64 \pm 0.07 \mathrm{gGAE} / \mathrm{ml}$ and $89.75 \pm 0.06 \%$, respectively.

\section{Riwayat Artikel \\ Dikirim : 01 Agustus, 2021 \\ Disetujui : 15 September, 2021 \\ Dipublis : 28 September, 2021}

Kata Kunci

Antioksidan; kombucha; lama fermentasi; lengkuas merah

\section{ABSTRAK}

Fermentasi merupakan salah satu cara untuk meningkatkan senyawa bioaktif pada berbagai produk pangan. Kombucha merupakan minuman yang dihasilkan dari fermentasi tradisional yang melibatkan fermentasi gula yang dilarutkan teh dengan kultur simbiosis bakteri dan ragi (SCOBY). Kombucha biasanya dibuat dari larutan teh dan belum banyak yang memanfaatkan rempah untuk pembuatan kombucha. Pada penelitian ini akan dibuat kombucha lengkuas merah. Metode yang digunakan adalah Rancangan Acak Lengkap (RAL) dengan variansi lama fermentasi (0, 2, 4, 6, 8 10) hari. Parameter yang akan dianalisis adalah $\mathrm{pH}$, total fenol, dan aktivitas antioksidan. Tujuan dari penelitian ini adalah mengetahui aktivitas antioksidan yang optimal dan pengaruh $\mathrm{pH}$ terhadap lama ferementasi pada kombucha lengkuas merah. Hasil yang diperoleh adalah lama fermentasi berpengaruh terhadap $\mathrm{pH}$, total fenolik dan aktivitas antioksidan minuman kombucha lengkuas merah. $\mathrm{pH}$ minuman kombucha lengkuas merah mengalami penurunan seiring dengan lama fermentasi. Total fenolik dan aktivitas antioksidan yang paling optimal diperoleh pada waktu lama fermentasi 8 hari sebesar $854,64 \pm 0,07 \mu \mathrm{gGAE} / \mathrm{ml}$ dan $89,75 \pm 0,06 \%$.

Sitasi: Hapsari, M., Rizkiprilisa, W., \& Sari, A. (2021). Pengaruh lama fermentasi terhadap aktivitas antioksidan minuman fermentasi kombucha lengkuas merah (Alpinia purpurata). Agromix, 12(2), 146-149. https://doi.org/10.35891/agx.v12i2.2647

\section{PENDAHULUAN}

Masyarakat mulai menyadari pentingnya mengonsumsi pangan yang tidak hanya memberikan efek mengenyangkan, tetapi memberikan efek yang baik bagi kesehatan tubuh. Pola konsumsi pangan yang buruk dan polusi menjadi salah satu timbulnya radikal bebas dalam tubuh (Devasagayam, 2004; Elkhateeb \& Alshammary, 2017). Radikal bebas ini mampu memicu berbagai penyakit degeneratif. Antioksidan menjadi salah satu senyawa yang mampu menstabilkan dan menangkal radikal bebas (Savitri \& suwita, 2017).

Lengkuas merah merupakan salah satu rempah-rempah yang dapat ditingkatkan nilai ekonomisnya menjadi pangan fungsional. Hasil penelitian Raj dkk. (2012) melaporkan bahwa lengkuas merah mengandung senyawa alkaloid, flavonoid dan terpenoid. Lengkuas merah juga mengandung senyawa alpinia, galangal, kamferol, dan steroid (Kusriani \& Zahra, 2015). Penelitian terdahulu juga menyebutkan bahwa lengkuas merah memiliki sifat antioksidan, antikanker, 
antidiabetes dan antimikrobia (Chan \& Wong, 2015). Adanya kandungan senyawa fenolik, flavonoid dan turunannya menjadikan lengkuas merah berpotensi menjadi antioksidan alami (Mayachiew \& Devahastin, 2008); Tang, 2018).

Fermentasi diyakini dapat meningkatkan senyawa bioaktif pada proses pengolahan pangan. Fermentasi pada kombucha teh dapat meningkatkan senyawa fenolik dan aktivitas antioksidan (Martínez Leal dkk., 2018). Kombucha adalah minuman yang dihasilkan dari fermentasi tradisional yang melibatkan fermentasi gula yang dilarutkan teh dengan kultur simbiosis bakteri dan ragi (SCOBY). Kombucha umumnya dibuat dari larutan teh dan belum banyak yang memanfaatkan tanaman rempah (Nurhaliza, 2020). Lengkuas merah yang sudah mengandung senyawa fenolik dan memiliki aktivitas antioksidan dapat ditingkatkan kembali senyawa fenoliknya dengan jalan fermentasi (John \& Deeseenthum, 2021). Pebiningru dkk. (2018) telah melakukan penelitian membuat kombucha jahe dan terbukti mengalami peningkatan aktivitas antioksidan sebesar $84,70 \%$. Penelitian kombucha dengan substrat gambir terbukti mengalami peningkatan pada aktivitas antioksidan (Leliqia, Susanti, \& Chanjaya, 2014). Oleh karena itu, pada penelitian ini akan dilakukan fermentasi kombucha lengkuas merah dengan lama fermentasi yang berbeda untuk mengetahui aktivitas antioksidan yang optimal dan pengaruh $\mathrm{pH}$ terhadap lama fermentasi.

\section{METODE}

\section{Bahan}

Bahan utama yang dibutuhkan dalam pembuatan kombucha ini adalah lengkuas merah, starter kombucha, dan gula. Lengkuas merah yang digunakan berumur empat bulan dan didapatkan dari Pasar Tawangmangu, Karanganyar. Starter kombucha didapatkan dari Market place.

\section{Prosedur penelitian}

Pembuatan minuman kombucha lengkuas merah dilakukan secara dua tahap yaitu pembuatan sari lengkuas merah dan pembuatan kombucha lengkuas merah. Pembuatan sari lengkuas merah dimulai dari pencucian lengkuas merah dari kotorannya, kemudian ditimbang sebanyak 200 gram. Selanjutnya, lengkuas merah diblender dengan perbandingan lengkuas merah : air sebanyak 1 : 2. Hasil pemblenderan disaring dengan menggunakan kain saring sehingga didapatkan sari lengkuas merah.

Pembuatan kombucha lengkuas merah dengan merebus sari lengkuas merah pada suhu $85^{\circ} \mathrm{C}$ selama 12 menit. Setelah dingin sari lengkuas merah dimasukkan dalam toples kaca dan ditambahkan gula 10\%. Dilakukan penambahan starter kombucha dan diinkubasi pada suhu $29-30^{\circ} \mathrm{C}$. Penyimpanan dilakukan di tempat yang minim cahaya dengan variasi lama fermentasi $(0,2,4,6,8$ dan 10$)$ hari. Pada setiap sampel dilakukan analisis $\mathrm{pH}$, antioksidan, total fenol dan total flavonoid.

\section{Rancangan percobaan}

Penelitian menggunakan desain penelitian Rancangan Acak Lengkap (RAL) menggunakan 6 taraf perlakuan lama fermentasi yaitu $(0,2,4,6$, 8 dan 10) hari. Parameter yang akan diukur adalah $\mathrm{pH}$, total fenolik, total flavonoid dan aktivitas antioksidan. Data yang diperoleh dihitung secara statistik dengan metode analisis varian pada tingkat kepercayaan 95\% dan dilanjutkan dengan analisis uji beda nyata menggunakan Duncan Multiple Range Test (DMRT).

\section{HASIL DAN PEMBAHASAN}

Hasil pengamatan kombucha lengkuas merah dengan variasi lama fermentasi (0, 2, 4, 6, 8 dan 10) hari terhadap $\mathrm{pH}$, total fenolik, total flavonoid dan aktivitas antioksidan dapat dilihat pada Tabel 1.

Tabel 1. Hasil pengamatan kombucha lengkuas merah

\begin{tabular}{cccc}
\hline Lama fermentasi (hari) & \multicolumn{3}{c}{ Parameter } \\
\cline { 2 - 4 } & $\mathrm{pH}$ & Total fenolik $(\mu \mathrm{gGAE} / \mathrm{ml})$ & Aktivitas Antioksidan (\%) \\
\hline 0 & $4,53 \pm 0,07$ & $759,36 \pm 0,06$ & $80,52 \pm 0,87$ \\
2 & $4,40 \pm 0,16$ & $780,69 \pm 0,03$ & $83,67 \pm 0,55$ \\
4 & $4,32 \pm 0,11$ & $805,73 \pm 0,16$ & $85,27 \pm 1,04$ \\
6 & $3,83 \pm 0,26$ & $824,79 \pm 0,16$ & $87,21 \pm 0,06$ \\
8 & $3,56 \pm 0,05$ & $854,64 \pm 0,07$ & $89,75 \pm 0,06$ \\
10 & $3,20 \pm 0,31$ & $734,62 \pm 1,15$ & $79,46 \pm 0,34$ \\
\hline
\end{tabular}

\section{Analisis pH}

Pada penelitian ini didapatkan rerata $\mathrm{pH}$ minuman kombucha lengkuas merah berkisar di nilai pH antara 3,20-4,53. Pada Tabel 1 dapat dilihat bahwa nilai $\mathrm{pH}$ semakin menurun seiring dengan lama fermentasi minuman kombucha lengkuas merah. Penurunan $\mathrm{pH}$ terjadi karena adanya pertumbuhan dan metabolisme dari starter kombucha yaitu yeast, bakteri asam asetat, bakteri asam laktat yang mengakibatkan peningkatan asam organik (Jayabalan dkk., 2014; 
Neffe-Skocińska dkk. 2017). Pada kombucha lokal dengan substrat gambir, seiring dengan lama fermentasi juga terjadi penurunan $\mathrm{pH}$ yang berkisar dari 3,4-2,5 (Leliqia dkk., 2014).

Pada kondisi aerobik starter kombucha mampu mengubah gula teh dalam jangka waktu 7 hingga 10 hari sehingga minuman akan menjadi sedikit asam, menghasilkan 14 asam amino, vitamin dan beberapa enzim hidrolitik (Malbaša dkk., 2011). Nilai pH menjadi salah satu parameter lingkungan yang paling penting dalam mempengaruhi fermentasi kombucha, karena terbentuk beberapa asam seperti asetat dan glukonat. Keasaman minuman kombucha yang layak dikonsumsi berkisar pada range $\mathrm{pH}$ 2,5-4,6.

\section{Total fenolik dan aktivitas antioksidan}

Pada penelitian ini, analisis total fenolik menggunakan metode folin-ciocalteu dan analisis antioksidan menggunakan metode DPPH. Fermentasi berkaitan dengan pertumbuhan mikroba dan perubahan senyawa fitokimia yang dapat mempengaruhi aktivitas antioksidan (Hur dkk., 2014). Perubahan pH selama fermentasi dapat meningkatkan aktivitas antioksidan dengan mengubah kandungan dan struktur senyawa fenolik (Martínez Leal dkk., 2018). Ada keterkaitan antara kandungan total fenol dengan aktivitas antioksidan. Semakin tinggi kandungan total fenol, semakin tinggi pula aktivitas antioksidannya.

Pada Tabel 1 menunjukkan bahwa lama fermentasi berpengaruh terhadap total fenolik dan aktivitas antioksidan minuman kombucha lengkuas merah. Pada lama fermentasi hari ke-0 sampai ke-8 terjadi peningkatan total fenolik dan aktivitas antioksidan yang signifikan. Pada fermentasi hari ke-10 terjadi penurunan total fenolik dan aktivitas antioksidan. Total fenolik pada hari ke-0 sebesar 759,36 $\pm 0,06 \mu \mathrm{gGAE} / \mathrm{ml}$ dan mengalami peningkatan sampai optimal pada hari ke-8 sebesar $854,64 \pm 0,07 \mu \mathrm{gGAE} / \mathrm{ml}$, lalu mengalami penurunan pada hari ke-10 menjadi $734,62 \pm 1,15$ $\mu g G A E / m l$. Aktivitas antioksidan juga mengalami peningkatan selama fermentasi dengan meningkatnya total fenolik yang dihasilkan. Aktivitas antioksidan tertinggi minuman kombucha lengkuas merah berada pada hari ke- 8 sebesar $89,75 \pm 0,06 \%$ dan mengalami penurunan pada hari ke-10 menjadi $79,46 \pm 0,34 \%$.

Peningkatan total fenol pada kombucha lengkuas merah dikarenakan selama fermentasi, enzim yang dibebaskan oleh bakteri dan khamir akan mendegradasi senyawa kompleks pada lengkuas merah seperti alpinia, galangin, kamferol menjadi senyawa yang sederhana. Menurut Coelho dkk., (2020) selama proses fermentasi, jumlah senyawa fenol meningkat akibat hidrolisis gula oleh yeast dan enzim bakteri asam laktat. Sedangkan, penurunan total fenolik dan aktivitas antioksidan di hari ke-10 dikarenakan suasana asam yang menyebabkan senyawa fenolik menjadi lebih stabil dan sulit melepaskan proton yang dapat berikatan dengan DPPH, sehingga aktivitas antioksidan menurun (Villarreal dkk., 2018). Mengkonsumsi kombucha yang difermentasi terlalu lama juga dapat berbahaya bagi kesehatan karena kandungan asam asetat yang tinggi dapat menyebabkan asidosis. Lama fermentasi kombucha yang direkomendasikan untuk bisa dikonsumsi manusia tidak boleh lebih dari 10 hari (Nummer, 2013; Nurhaliza, 2020).

Menurut Chakravorty dkk., (2019) kandungan polifenol dan aktivitas antioksidan pada kombucha teh meningkat pada hari ke-7 selama fermentasi, yang disebabkan oleh adanya metabolisme mikroorganisme dalam kombucha selama proses fermentasi. Aktivitas antioksidan kombucha dari berbagai jenis daun teh mengandung fenol dengan aktivitas antioksidan sebesar $88,24 \%-92,97 \%$ selama fermentasi 8 hari dan mengalami penurunan aktivitas antioksidan di hari ke-14 (Puspitasari dkk., 2017; Suhardini \& Zubaidah, 2015). Aktivitas antioksidan pada kombucha jahe sebesar 84,70\% pada lama fermentasi 12 hari (Pebiningrum dkk., 2018).

\section{KESIMPULAN}

Lama fermentasi berpengaruh terhadap $\mathrm{pH}$, total fenolik dan aktivitas antioksidan minuman kombucha lengkuas merah. pH minuman kombucha lengkuas merah mengalami penurunan seiring dengan lama fermentasi. Total fenolik dan aktivitas antioksidan yang paling optimal diperoleh pada waktu lama fermentasi 8 hari sebesar $854,64 \pm 0,07 \mu \mathrm{gGAE} / \mathrm{ml}$ dan $89,75 \pm 0,06 \%$.

\section{DAFTAR PUSTAKA}

Chakravorty, S., Bhattacharya, S., Bhattacharya, D., Sarkar, S., \& Gachhui, R. (2019). Kombucha: a promising functional beverage prepared from tea. In Non-alcoholic beverages (pp. 285-327). Woodhead Publishing. https://doi.org/10.1016/B978-0-12-815270-6.00010-4

Chan, E. W. C., \& Wong, S. K. (2015). Phytochemistry and pharmacology of ornamental gingers, Hedychium coronarium and Alpinia purpurata: a review. Journal of Integrative Medicine, 13(6), 368-379. https://doi.org/10.1016/S2095-4964(15)60208-4

Coelho, R. M. D., Almeida, A., do Amaral, R. Q. G., da Mota, R. N., \& de Sousa, P. H. M. (2020). Kombucha: review. International Journal of Gastronomy and Food Science, 100272, 1-12. https://doi.org/10.1016/j.ijgfs.2020.100272

Devasagayam, T. P. A., Tilak, J. C., Boloor, K. K., Sane, K. S., Ghaskadbi, S. S., \& Lele, R. D. (2004). Free radicals and antioxidants in human health: current status and future prospects. Japi, 52(794804), 4.

Elkhateeb, Y. A. M., \& Alshammary, M. R. (2017). Effects of Fast Foods in Relation to Free Radicals and 
Antioxidants. American Journal of Laboratory Medicine, 2(6), 156-162.

Hur, S. J., Lee, S. Y., Kim, Y.-C., Choi, I., \& Kim, G.-B. (2014). Effect of fermentation on the antioxidant activity in plantbased foods. Food Chemistry, 160, 346-356. https://doi.org/https://doi.org/10.1016/j.foodchem.2014.03.112

Jayabalan, R., Malbaša, R. V, Lončar, E. S., Vitas, J. S., \& Sathishkumar, M. (2014). A review on kombucha teamicrobiology, composition, fermentation, beneficial effects, toxicity, and tea fungus. Comprehensive Reviews in Food Science and Food Safety, 13(4), 538-550. https://doi.org/10.1111/1541-4337.12073

John, S. M., \& Deeseenthum, S. (2021). Characteristics and Chemical Compositions of Rice Milk Kefir and Process Optimization to Obtain High Antioxidant Kefir [Doctoral dissertation]. Mahasarakham University.

Kusriani, R. H., \& Zahra, S. A. (2015). Skrining fitokimia dan penetapan kadar senyawa fenolik total ekstrak rimpang lengkuas merah dan rimpang lengkuas putih (Alpinia galanga L.). Prosiding SNaPP: Kesehatan (Kedokteran, Kebidanan, Keperawatan, Farmasi, Psikologi), 1(1), 295-302.

Leliqia, N. P. E., Susanti, N. M. P., \& Chanjaya, C. (2014). Pengaruh lama fermentasi terhadap aktivitas antioksidan minuman kombucha lokal di Bali dengan substrat produk gambir. J. Farm. Udayana, 3, 116-119.

Malbaša, R. V, Lončar, E. S., Vitas, J. S., \& Čanadanović-Brunet, J. M. (2011). Influence of starter cultures on the antioxidant activity of kombucha beverage. Food Chemistry, 127(4), 1727-1731. https://doi.org/10.1016/j.foodchem.2011.02.048

Martínez Leal, J., Valenzuela Suárez, L., Jayabalan, R., Huerta Oros, J., \& Escalante-Aburto, A. (2018). A review on health benefits of kombucha nutritional compounds and metabolites. CyTA-Journal of Food, 16(1), 390-399. https://doi.org/https://doi.org/10.1080/19476337.2017.1410499

Mayachiew, P., \& Devahastin, S. (2008). Antimicrobial and antioxidant activities of Indian gooseberry and galangal extracts. LWT-Food Science and Technology, 41(7), 1153-1159.

Neffe-Skocińska, K., Sionek, B., Ścibisz, I., \& Kołożyn-Krajewska, D. (2017). Acid contents and the effect of fermentation condition of Kombucha tea beverages on physicochemical, microbiological and sensory properties. CyTA-Journal of Food, 15(4), 601-607. https://doi.org/10.1080/19476337.2017.1321588

Nummer, B. A. (2013). Special report: Kombucha brewing under the food and drug administration model food code: risk analysis and processing guidance. Journal of Environmental Health, 76(4), 8-11.

Nurhaliza, T. (2020). Pembuatan teh kombucha dari daun pegagan (Centella asiatica) VARIASI waktu fermentasi dan konsentrasi larutan teh kombucha [Doctoral dissertation]. Politeknik Negeri Sriwijaya.

Pebiningrum, A., Kusnadi, J., \& Rif'ah, H. I. (2018). Pengaruh varietas jahe (Zingiber officinale) dan penambahan madu terhadap aktivitas antioksidan minuman fermentasi kombucha jahe. Journal of Food and Life Sciences, 1(2), 33-42. http://dx.doi.org/10.21776/ub.jfls.2017.001.02.01

Puspitasari, Y., Palupi, R., \& Nurikasari, M. (2017). Analisis kandungan vitamin C teh kombucha berdasarkan lama fermentasi sebagai alternatif minuman untuk antioksidan. Global Health Science (GHS), 2(3), $245-253$. http://dx.doi.org/10.33846/ghs.v2i3.137

Raj, C. A., Ragavendran, P., Sophia, D., Rathi, M. A., \& Gopalakrishnan, V. K. (2012). Evaluation of in vitro antioxidant and anticancer activity of Alpinia purpurata. Chinese Journal of Natural Medicines, 10(4), $263-268$. https://doi.org/10.1016/S1875-5364(12)60053-3

Savitri, L. P. A. D., \& Suwita, I. K. (2017). Pengaruh substitusi jus kulit buah naga merah (Hylocereus polyrhyzus) dan penambahan bekatul terhadap aktivitas antioksidan, kadar serat, dan mutu organoleptik mie basah sehat. Agromix, 8(1), 1-12. https://doi.org/10.35891/agx.v8i1.559

Suhardini, P. N., \& Zubaidah, E. (2015). Studi aktivitas antioksidan kombucha dari berbagai jenis daun selama fermentasi [in press januari 2016]. Jurnal Pangan dan Agroindustri, 4(1), 221-229.

Tang, X., Xu, C., Yagiz, Y., Simonne, A., \& Marshall, M. R. (2018). Phytochemical profiles, and antimicrobial and antioxidant activities of greater galangal [Alpinia galanga (Linn.) Swartz.] flowers. Food chemistry, 255, $300-308$.

Villarreal-Soto, S. A., Beaufort, S., Bouajila, J., Souchard, J., \& Taillandier, P. (2018). Understanding kombucha tea fermentation: a review. Journal of Food Science, 83(3), 580-588. https://doi.org/10.1111/1750-3841.14068 